\title{
Use of yield-yield correlation for early selection of newly developed Hevea genotypes
}

\author{
S P Withanage*, H P Peiris*, L S Kariyawasam*, I D M J Sarath Kumara*, \\ T M S K Gunasekara* and B W A N Baddewithana* \\ * Rubber Research Institute of Sri Lanka, Nivithigalakele, Matugama \\ Received: 29April 2014
}

\begin{abstract}
In Hevea breeding and selection procedure, evaluation of genetic potential of newly developed genotypes under small scale clonal trials takes a minimum of 10-12 years. With the objective of shortening this period, statistical analysis of yield of thirteen years old 102 different Hevea genotypes belonging to three hand pollinated progenies established at Kalutara and Ratnapura districts was conducted. The effects of genotype, year and genotype versus year interaction were highly significant for all three progenies for girth and yield. Phenotypic correlation coefficients revealed significant yield -yield correlation between yields of $5^{\text {th }} / 7^{\text {th }}$ year tapping and yields of younger tapping years. Spearman's rank correlation coefficients were significant for all combinations tested except first year yield of progeny $90 \mathrm{HP}$ at Kuruwita. Starting early selection of best thirty percent of genotypes at the end of first year of tapping based on Spearman ranks of genotypes, it would be able to select successfully around $33.4 \%$ to $54.6 \%$ of genotypes, nearly 6 years earlier than the general selection procedure. Subsequent selections can be added later for further testing and nearly 90\% of selections are possible before the final selection point. In two progenies tested it was possible to select nearly $81 \%$ of the genotypes by the second year of tapping where as in the other progeny the portion selected was 46.4\%. In subsequent selection steps, success of selection was increased which decreased the selection wastage. The evaluation process can be accelerated by $6-7$ years by taking these selections to an "interim clone recommendation" for further evaluation under large scale estates in collaboration with the Rubber Research Institute. It maximizes the gain per unit time of Hevea breeding and shortens the evaluation process.
\end{abstract}

Key words: breeding, early selection, Hevea, yield 


\section{Introduction}

Hevea brasiliensis (Muell. Arg.) is the major source for natural rubber. It has been introduced to Sri Lanka in 1876 by Sir Henry Wickham. Starting from these unselected seedlings which yielded around 300-400 kg/ha/year (Jayasekara and Fernando, 1984), today it has been raised up to $3000-3500 \mathrm{~kg} / \mathrm{ha} /$ year, with genetically improved planting material. This success was gained almost through the breeding effort of Hevea during past 100 years. But it is a well known fact that Hevea breeding is a difficult task because of its perennial nature. The conventional Hevea breeding programme starts from the annual hand pollination (artificial pollination) program carried in each year to develop new genotypes. It takes at least 20-25 years to complete one breeding cycle (Fig. 1). In this breeding procedure, from hand pollination to first step of selection at mother plant nursery, it takes minimum of 4 years. Then the selected genotypes are transferred to the evaluation step of Small Scale Clonal Trials (SSCTs). The genetic potential of genotypes is evaluated for another 1215 years. Then the selected genotypes which have good genetic potential are selected and evaluated under commercial level by the Rubber Research Institute (RRI) with the collaboration of Regional Plantation Companies (RPCs) as Estate Collaborative Trials with Rubber Research Institute (ECTs/RRI) for further 10-12 years until the recommendation is made for group III level of clone recommendation (Fig. 1). Once the selection decision is made at the end of SSCTs level, the vegetative multiplication and preparation of bud woods and planting material for the next step (ECTs/RRI) of evaluation takes another few years in addition to this speculated time of Small Scale Trials.

This long time consuming process can be accelerated by applying early selection of superior genotypes. Wu (1998) has discussed the theoretical base of this early selection. Advantages and procedures of early selection in tree breeding have been discussed by many workers (Matheson et al., 1994: Adams and Aitken, 1982). This study employed girth-girth, girth-yield and yield-yield correlations and Spearmen's rank correlation coefficient on ranked data of girth and yield of genotypes as an attempt to adopt early selection in Hevea breeding to shorten the long evaluation period. 


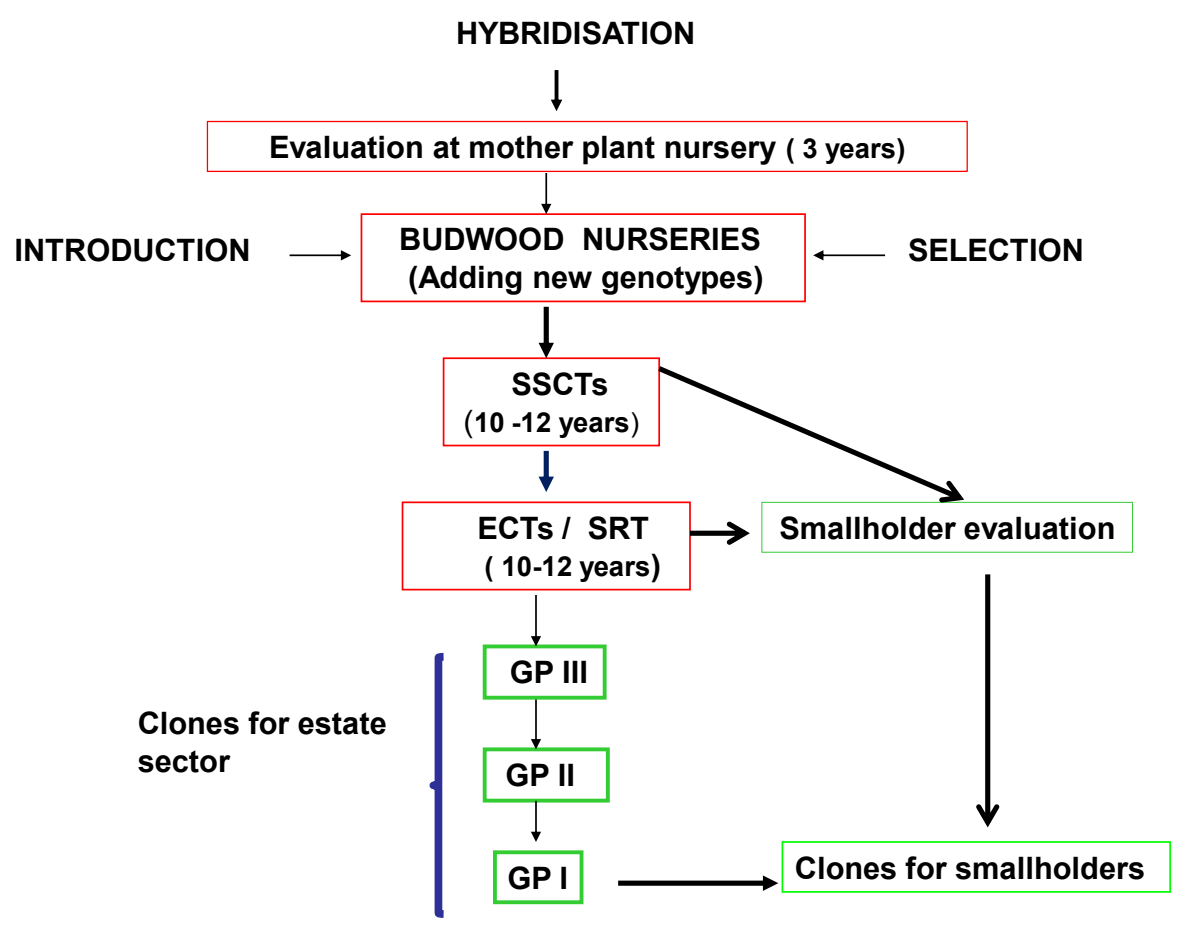

Fig. 1. General breeding procedure: Testing duration along with different evaluation steps in main conventional breeding procedure. SSCTs; small scale clonal trials, ECT/RRI; Estate/RRI colaborative trials, GP; group

\section{Materials and Methods}

In this study, 102 different genotypes developed by 1990 (25 genotypes), 1991 (29 genotypes) and 1996 (48 genotypes) hand pollination progenies along with four control clones as RRIC 121, RRIC 130, PB 260 and RRISL 205 were used. These small scale clonal evaluation trials were established at Pallegoda estate in Kalutara district and at Kuruwita Substation of the Rubber Research Institute of Sri Lanka (RRISL) in Ratnapura district. In all these trials a fully randomized design was used with 15 to 20 replicate for each genotype. All agronomic practices were carried out according to the recommendations made by RRISL.

Annual girth was measured for thirteen years in each individual at the height of $120 \mathrm{~cm}$ above the bud union. Tapping was commenced at the age of 5 years when more than $60 \%$ of the trees reached $45-50 \mathrm{~cm}$ of girth. Half spiral 
alternative day intervals $(\mathrm{S} / 2 \mathrm{~d} 2)$ tapping system was applied. Latex collection was made into individual cups and coagulated by adding $2.5 \%(\mathrm{v} / \mathrm{v})$ acetic acid solution once latex flow had stopped. The coagulum made as a disc and dried in the smoke house until a constant weight is attained. This cup coagulated dry rubber weight was recorded twice a month in normal tapping days and covered the twelve months for the year to get annual average yield. Yield over first seven years of tapping was recorded except for 90 HP Kuruwita in which yield data of only first 5 years of were recorded.

\section{Statistical analysis}

Analysis of variance (ANOVA) was done for annual girth measurements taken for thirteen years and annual yield data for 5 years in the case of $90 \mathrm{HP}$ Kuruwita and for 7 years in other two progenies. The Spearman's rank correlation coefficient $\left(r_{s}\right)$ was computed for both traits (GenStat Release 16.2 VSN International Ltd). Immature girth was recorded from first year after planting up to fifth year (girth at opening) after planting. For yield it was between age at 12 or $7^{\text {th }}$ year of tapping (where normally selection of SSCT evaluation is done) and early tapping years. Rank 1 was given to the highest value (girth/yield) whereas highest rank given to the lowest girth/yield within each age for a given trait. Fisher's table XXV was used to test the significance (Fisher 1941).

In normal selection procedure, the final selection of this SSCTs evaluation was made at the $7^{\text {th }}$ year of mean yields at the 13 years of age of trees. In this study, we made selection earlier using the Spearman ranks of each genotype of each progeny from first year of yield to sixth year of yield. During this early selection procedure, using the Spearman ranks of each genotype, the selection chance of each genotype in each year is the chance to get selected into a final selection list (which made according to normal selection procedure after fifth or seventh year yield). Similarly the selection wastage is the possibility of early selection not to get into the final selection list. These figures of each genotype for each year were calculated as a percentage. However, to balance the selection success and wastage it has been pre decided to select around best $30-35 \%$ of progeny in each selection, irrespective of the number of genotypes under evaluation. But still mean yield performances of these selections and their Duncan groups (data not shown) were compared with control clones to decide this amount. Accordingly from the progenies of 90HP Kuruwita and 91HP Pallegoda, there were 11 genotypes (approximately 35\%) and from the progeny 96HP Kuruwita around 15 genotypes (approximately $30 \%$ ) were selected every year. The scatter diagrams between ranks of yield 
of $5^{\text {th }} / 7^{\text {th }}$ year of tapping and younger yields were plotted.

\section{Results and Discussion}

The phenotypic correlation coefficients $\left(r_{p}\right)$ among yields of different years and yield of final year $\left(5^{\text {th }} / 7^{\text {th }}\right)$ of tapping in different locations are given in Table 1. The $r_{p}$ values for yield ranged from 0.08 (yield of first year of tapping at age 6) to 0.75 (yield of $4^{\text {th }}$ year of tapping at age 10) for the progeny Kuruwita (90HP) when correlated with yield at $5^{\text {th }}$ year of tapping. The $r_{p}$ value changed from 0.31 (yield of first year of tapping at age 6) to 0.77 (yield of $6^{\text {th }}$ year of tapping at age 11) for the progeny at Pallegoda (91HP) with reference to the yield at seventh year of tapping. Correlation coefficient ranged from 0.26 (yield of first year of tapping at age 6) to 0.67 (yield of $6^{\text {th }}$ year of tapping at age 11) for the progeny at Kuruwita $(96 \mathrm{HP})$ with reference to yield of $7^{\text {th }}$ year of tapping (Table 1).

The positive phenotypic yield-yield correlations imply the possibility of selecting genotypes in early years for that particular trait. Although there have been attempts made to employ girth-yield relationships, many workers have reported low correlations between girth in immature period vs. yield (Goncalves et al., 2005). This study recorded a low correlation coefficient of 0.240 between girth at age of opening of tapping and yield of 7/5 year of tapping. Hence, it is preferable to use yield as the main selection criterion during this genetic potential evaluation step (SSCTs) rather than selection based on girth.

Table 1. Phenotypic correlation coefficients $\left(r_{p}\right)$ between $5^{\text {th }} / 7^{\text {th }}$ year yields and yields of younger tapping years for different progenies in Kuruwita and Pallegoda

\begin{tabular}{llll}
\hline Yields obtained in & \multicolumn{3}{c}{ Sites } \\
\cline { 2 - 4 } $\begin{array}{l}\text { Different years after } \\
\text { commencement of tapping }\end{array}$ & $\begin{array}{l}\text { Kuruwita } \\
\mathbf{9 0 H P}\end{array}$ & $\begin{array}{l}\text { Pallegoda } \\
\mathbf{9 1 H P}\end{array}$ & $\begin{array}{l}\text { Kuruwita } \\
\mathbf{9 6 H P}\end{array}$ \\
\cline { 2 - 4 } & $\mathbf{5}^{\text {th }}$ year yield & $\mathbf{7}^{\text {th }}$ year yield & $\mathbf{7}^{\text {th }}$ year yield \\
\hline $1^{\text {st }}$ Year & 0.08 & $0.31 * *$ & $0.26 * *$ \\
$2^{\text {nd }}$ Year & $0.31 * *$ & $0.39 * *$ & $0.39 * *$ \\
$3^{\text {rd }}$ Year & $0.58 * *$ & $0.41 * *$ & $0.41 * *$ \\
$4^{\text {th }}$ Year & $0.75 * *$ & $0.44 * *$ & $0.52 * *$ \\
$5^{\text {th }}$ Year & - & $0.57 * *$ & $0.56 * *$ \\
$6^{\text {th }}$ Year & - & $0.77^{* *}$ & $0.67 * *$ \\
\hline
\end{tabular}

** Significant at $\mathrm{p}<0.001, \mathrm{~N}=28$ in 90HP Kuruwita, $\mathrm{N}=31$ in 91HP Pallegoda and $\mathrm{N}=51$ in 96 HP Kuruwita 
Although $r_{p}$ values were significant for all yield combinations, the order of ranks changes with years. The scatter diagrams of three progenies (Fig. 2a, 2b and 2c) depicting the relationship between ranks for final selection of genotypes and ranks obtained for yields for early years of tapping indicate the increasing agreement with ranks of the final selection $\left(5^{\text {th }} / 7^{\text {th }}\right.$ year of tapping). This suggests that early selection procedure may be successful, yet it becomes more successful when it comes to later years.

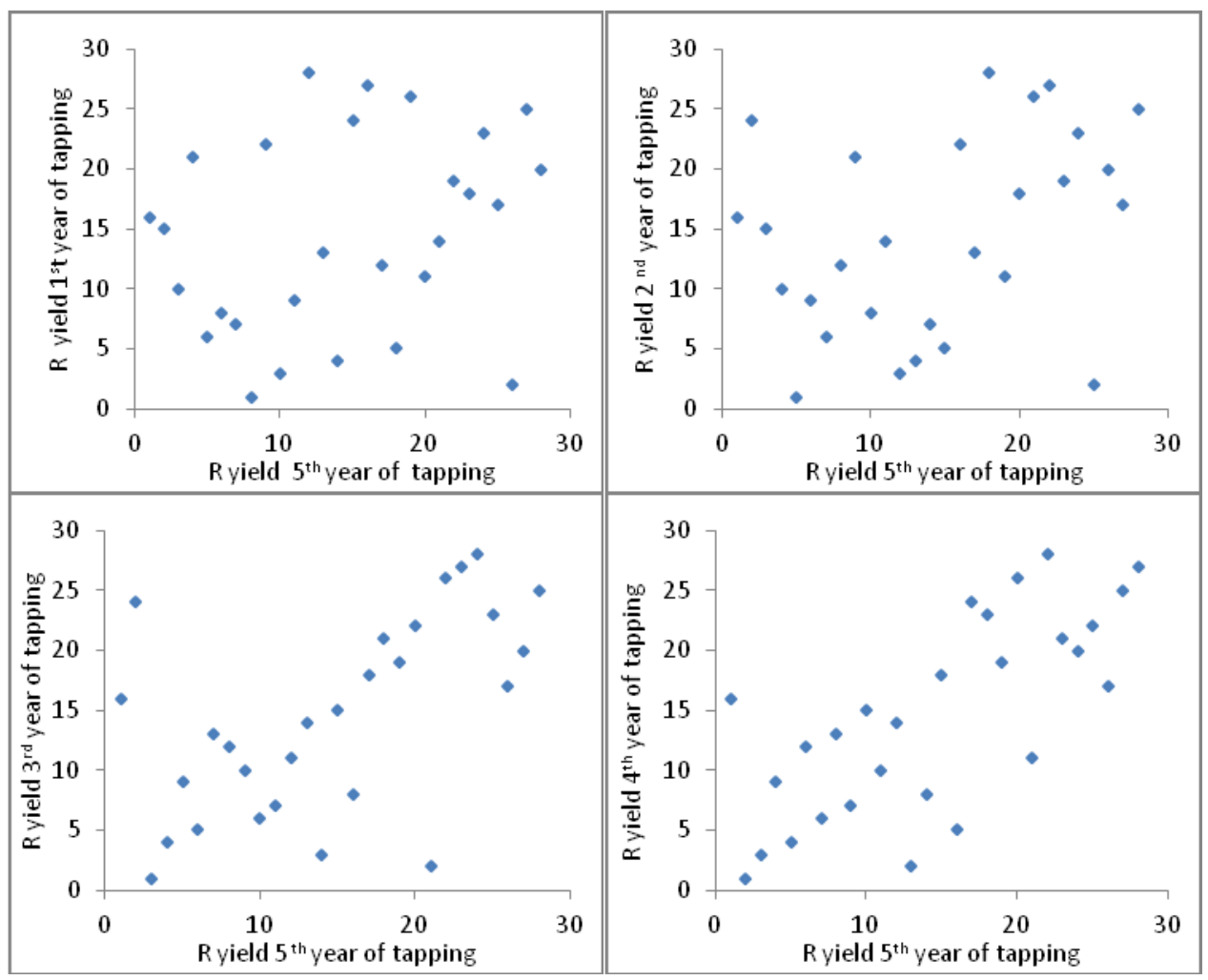

Fig. 2a. Scatter diagrams of ranks obtained for different years against the rank of the yield at $5^{\text {th }}$ year of tapping for 28 genotypes, including three control clones (RRIC 121, RRIC 130 and RRISL 205) in hand pollination progeny 1990 at Kuruwita (90 HP Kuruwita). 


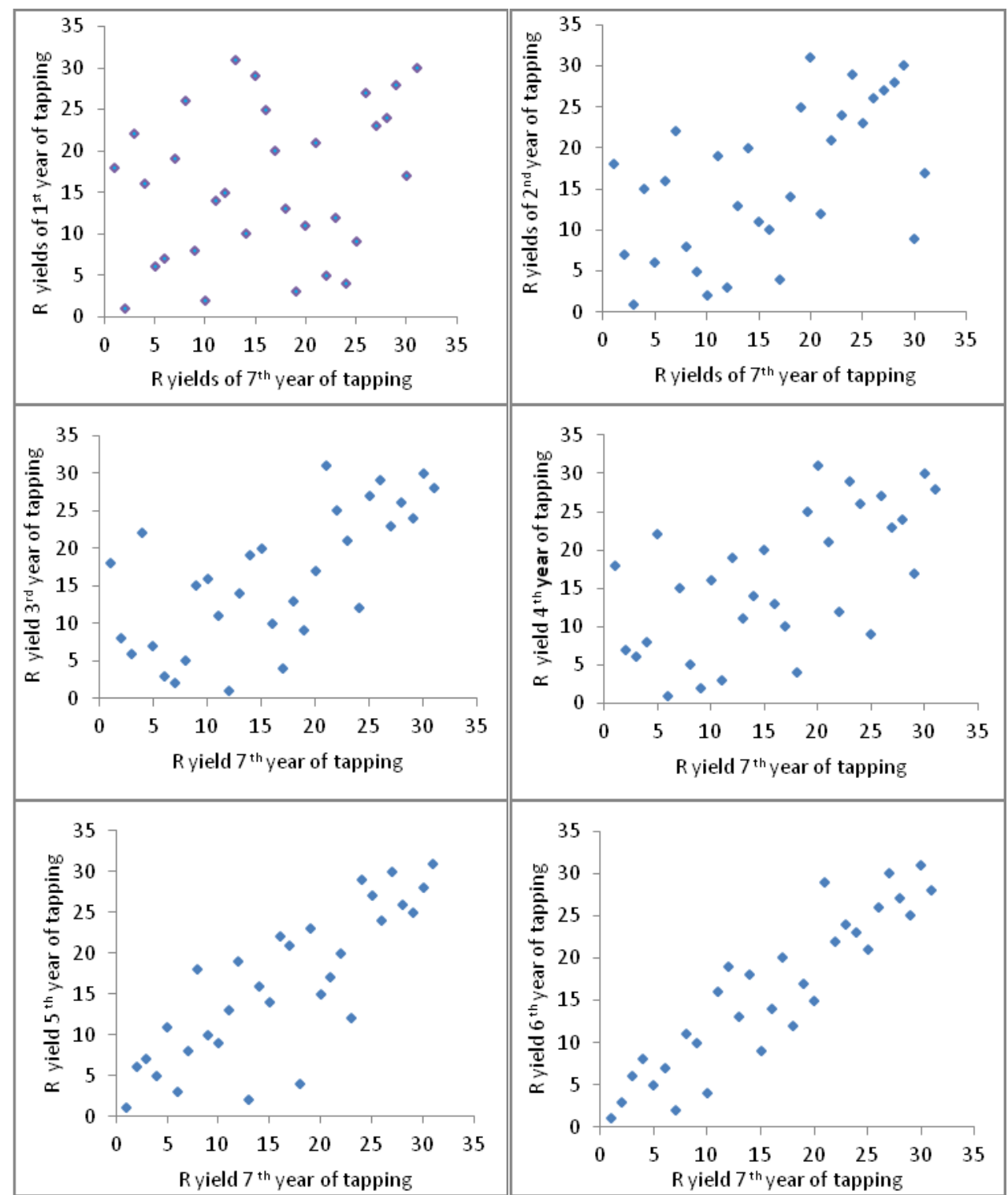

Fig. 2b. Scatter diagrams of ranks obtained for different years against the rank of the yield at $7^{\text {th }}$ year of tapping for 31 genotypes, including two control clones (RRIC 121 and RRISL 205) in hand pollination progeny 1991 at Pallegoda (91HP Pallegoda) 


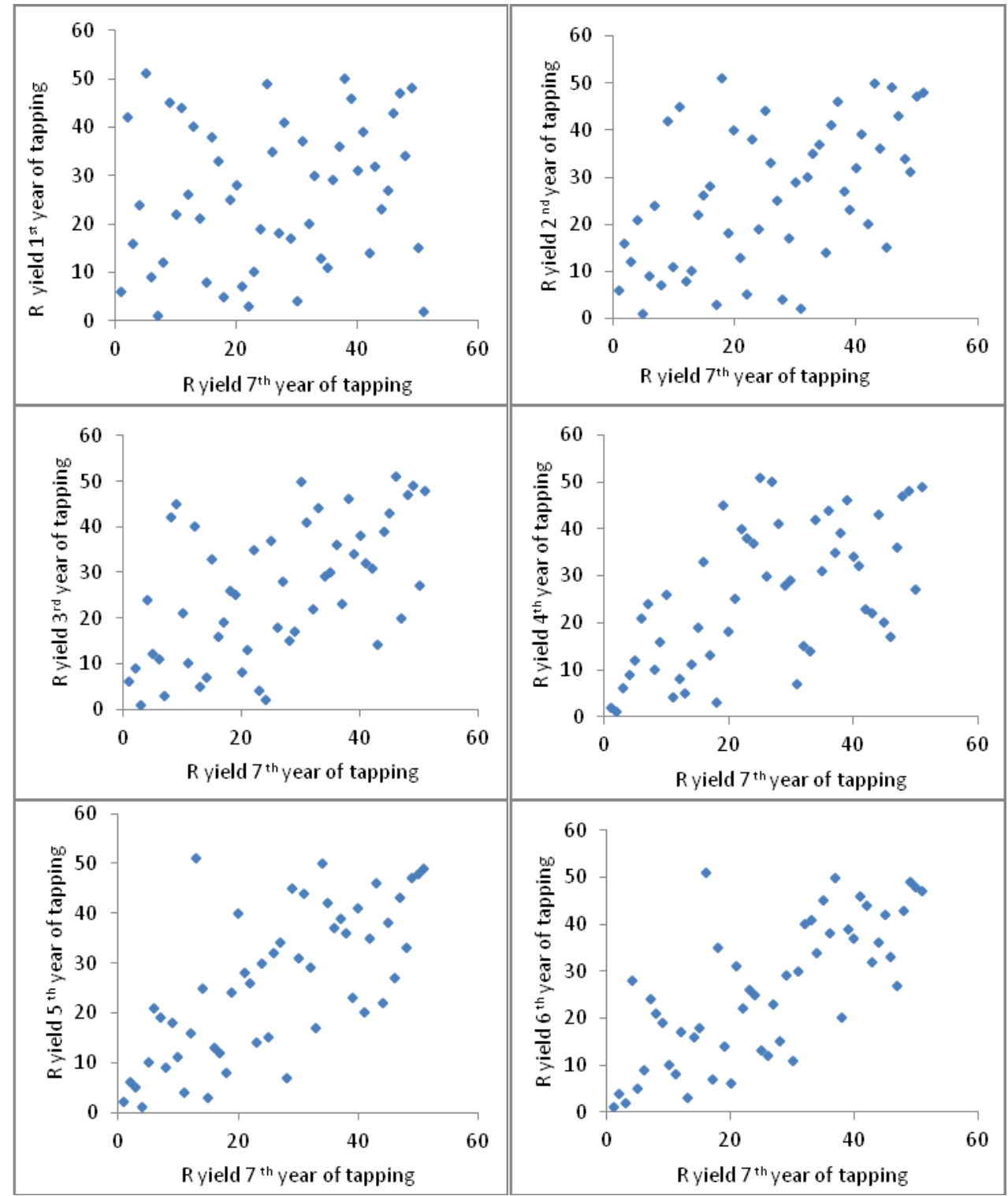

Fig. 2c. Scatter diagrams of ranks obtained for different years against the rank of the yield at $7^{\text {th }}$ year of tapping for 51 genotypes, including three control clones (PB 260, RRIC 121 and RRISL 205) in hand pollination progeny 1996 at Kuruwita (96HP Kuruwita) 
The difficult task is to decide the proportion of selections needs to be made at a particular age from which a substantial portion is correctly selected at the final selection point in order to minimize the selection waste. It is observed that when making selections at early stages, there is a need to select a large number of genotypes and can be gradually reduced at late selection ages. Goncalves et al. (2005) have observed a similar trend when making selections based on age-age correlation of Hevea.

Tables 2a, 2b and 2c show the successful early selection procedure for mean yield, based on rank correlations, from first year until to the final selection step (under normal selection procedure) in progeny of $90 \mathrm{HP}$ Kuruwita, 91HP Pallegoda and 96HP Kuruwita respectively. In first selection (S1) after first year of tapping, best 11 or 15 genotypes (around $30 \%$ or $35 \%$ of the each progeny) were selected. Then during subsequent selections (S2, S3, S4, S5 and S6) only new genotypes which are not included into the previous selections were added by following selections according to the ranks of that particular year.

Table 2a. The successful early selection for mean yield in progeny 90HP Kuruwita. Top ranked eleven genotypes selected in five consecutive years are shown as S1 to S5

\begin{tabular}{llllll}
\hline Rank & \multicolumn{5}{c}{ Year of selection } \\
\cline { 2 - 6 } & $1-S 1$ & $2-S 2$ & $3-S 3$ & $4-S 4$ & $5-S 5 /$ Final \\
\hline 1 & $90-15$ & $90-15$ & $90-23$ & $90-7$ & RRIC 130 \\
2 & $90-16$ & $90-2$ & $90-28$ & $90-13$ & $90-28$ \\
3 & $90-18$ & $90-13$ & $90-2$ & RRIC 130 & $90-7$ \\
4 & $90-5$ & $90-6$ & $90-4$ & $90-28$ & $90-10$ \\
5 & $90-20$ & $90-10$ & $90-13$ & $90-2$ & $90-13$ \\
6 & $90-28$ & $90-16$ & $90-7$ & $90-15$ & $90-23$ \\
7 & $90-6$ & $90-4$ & $90-10$ & RRIC 121 & $90-18$ \\
8 & $90-10$ & $90-20$ & $90-15$ & $90-23$ & $90-20$ \\
9 & $90-11$ & $90-17$ & RRIC 121 & $90-29$ & $90-17$ \\
10 & RRIC 121 & $90-23$ & $90-21$ & $90-21$ & $90-2$ \\
11 & $90-29$ & $90-28$ & $90-11$ & $90-8$ & RRIC 121 \\
\hline
\end{tabular}

Selections were marked in colours as S1, S2, S3, S4 and S5 
S P Withanage et al.

Table 2b. The successful early selection for mean yield in progeny $91 \mathrm{HP}$ Pallegoda. Top ranked eleven genotypes selected in seven consecutive years are shown as S1 to S7

\begin{tabular}{|c|c|c|c|c|c|c|c|}
\hline \multirow{2}{*}{ 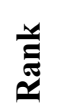 } & \multicolumn{7}{|c|}{ Year of selection } \\
\hline & 1-S1 & 2-S2 & 3-S3 & 4-S4 & 5-S5 & 6-S6 & 7-S7/Final \\
\hline 1 & 91-21 & $91-21$ & 91-21 & 91-21 & $91-4$ & RRISL205 & RRISL205 \\
\hline 2 & $91-24$ & $91-16$ & RRIC121 & $91-16$ & 91-1 & RRIC121 & RRIC121 \\
\hline 3 & 91-19 & 91-29 & RRISL205 & RRIC121 & 91-13 & 91-13 & 91-12 \\
\hline 4 & 91-16 & 91-13 & 91-19 & 91-24 & 91-9 & 91-19 & 91-13 \\
\hline 5 & $91-13$ & RRIC121 & $91-24$ & $91-29$ & $91-2$ & $91-4$ & 91-19 \\
\hline 6 & $91-36$ & 91-19 & 91-29 & 91-19 & 91-19 & 91-1 & 91-1 \\
\hline 7 & $91-4$ & 91-1 & 91-18 & RRISL205 & RRIC121 & 91-12 & 91-17 \\
\hline 8 & $91-8$ & $91-12$ & $91-16$ & $91-4$ & RRISL205 & $91-29$ & 91-29 \\
\hline 9 & RRISL205 & 91-7 & $91-4$ & 91-12 & 91-18 & 91-17 & 91-16 \\
\hline 10 & 91-7 & 91-24 & $91-12$ & 91-8 & 91-29 & 91-16 & $91-46$ \\
\hline 11 & 91-1 & RRISL205 & 91-8 & 91-13 & 91-21 & 91-2 & 91-21 \\
\hline
\end{tabular}

Selections were marked in colours as S1, S2, S3, S4, S5, S6 and S7

Table 2c. The successful early selection for mean yield in progeny 96HP Kuruwita. Top ranked eleven genotypes selected in seven consecutive years are shown as S1 to S7

\begin{tabular}{|c|c|c|c|c|c|c|c|}
\hline \multirow[t]{2}{*}{ Rank } & \multicolumn{7}{|c|}{ Year of selection } \\
\hline & 1-S1 & $2-\mathrm{S} 2$ & 3-S3 & 4-S4 & 5-S5 & 6-S6 & 7-S7/Final \\
\hline 1 & $96-22$ & $96-58$ & $96-58$ & $96-58$ & RRIC 121 & 96-14 & 96-58 \\
\hline 2 & $96-58$ & $96-54$ & 96-14 & 96-14 & $96-58$ & $96-15$ & 96-14 \\
\hline 3 & $96-24$ & 96-22 & $96-8$ & $96-54$ & $96-54$ & RRIC 121 & $96-8$ \\
\hline 4 & $96-54$ & 96-14 & $96-65$ & $96-65$ & $96-59$ & $96-65$ & $96-15$ \\
\hline 5 & 96-31 & $96-24$ & 96-31 & 96-18 & 96-14 & 96-59 & RRIC 121 \\
\hline 6 & 96-14 & 96-31 & RRIC 121 & RRIC 121 & $96-20$ & $96-54$ & $96-65$ \\
\hline 7 & $96-2$ & $96-65$ & $96-54$ & $96-15$ & 96-39 & $96-58$ & $96-20$ \\
\hline 8 & $96-65$ & $96-40$ & $96-15$ & 96-20 & $96-65$ & $96-2$ & $96-54$ \\
\hline 9 & $96-7$ & $96-20$ & $96-2$ & $96-39$ & 96-37 & $96-8$ & $96-26$ \\
\hline 10 & $96-56$ & 96-32 & $96-3$ & $96-59$ & $96-8$ & $96-16$ & $96-57$ \\
\hline 11 & 96-32 & 96-39 & $96-45$ & $96-3$ & $96-15$ & $96-43$ & $96-59$ \\
\hline 12 & 96-18 & $96-57$ & $96-20$ & $96-43$ & $96-3$ & $96-33$ & $96-33$ \\
\hline 13 & $96-33$ & $96-33$ & 96-59 & $96-8$ & $96-47$ & 96-10 & 96-37 \\
\hline 14 & 96-3 & $96-2$ & $96-24$ & $96-2$ & $96-40$ & $96-20$ & $96-44$ \\
\hline 15 & 96-16 & $96-56$ & 96-25 & 96-33 & $96-44$ & 96-37 & $96-47$ \\
\hline
\end{tabular}

Selections were marked in colours as S1, S2, S3, S4, S5, S6 and S7 
As an example, in the progeny $91 \mathrm{HP}$ Pallegoda, (Table 2b) once S1 selection step was done 11 genotypes were selected ( 91-21, 91-24, 91-19, 9116, 91-13, 91-36, 91-4, 91-8, RRISL 205, 91-7 and 91-1- marked in yellow), in the next step S2, three new genotypes (91-29, RRIC 121 and 91-12green) which have been included to top 11 ranks by displacing early selected three genotypes (91-36, 91-4 and 91-8). Then these three new genotypes can be selected at this stage. In the step S3, only a single genotype (91-18 - purple) was added to top 11 ranks and in the step S4, there were no new genotypes selected. But in the step S5 again two new genotypes (91-9, 91-2 - blue) were added whereas one genotype of S2 selection (91-12) was again displaced. Similarly, in the S6 selection step, the genotype (91-18) which was selected in the step S3 and one from S5 selection (91-9) were displaced. The genotype 91-12 which displaced at S5 was added again and a single new genotype (91-17) was added other than 6 genotypes (yellow) left from $\mathrm{S} 1$ selection. At the final selection point (or the normal Selection point at year 7) it can be concluded that already 6 (S1- Yellow), 3 (S2-Green) and one (S6-Ash) genotypes from selection step $\mathrm{S} 1, \mathrm{~S} 2$ and $\mathrm{S} 6$ have been selected respectively and other than this, only the genotype 91-46 which was escaped from the early selection procedure was there (missed the early selection).

Table 3 shows selection success, selection wastage and missed selection in three progenies by selecting approximately $30-35 \%$ of progeny in each selection step. If it is selected top ranked eleven genotypes from each progeny 90HP Kuruwita and 91HP Pallegoda and fifteen genotypes from progeny 96HP Kuruwita by evaluating first year yield, out of this there are five, six and again five genotypes were left in progenies of 90HP Kuruwita, 91HP Pallegoda and 96HP Kuruwita respectively at the final point of selection list.

As a percentage out of final selection, this selection success was $45.4 \%$ in progeny 90HP Kuruwita and 54.6\% in progeny 91HP Pallegoda. Whereas it was $33.4 \%$ in the progeny $96 \mathrm{HP}$ Kuruwita, even though greater number (15) of genotypes were selected. This is different from the results observed by Goncalves et al. (2005), as they found the increase of selection success with increased number of selections done at early stages based on girth of Hevea clones. But here we have analyzed hand pollination progenies which are having very high coefficient of variance among genotypes, which may be the reason for this disparity. 
Table 3. Selection success, waste and missed selections of subsequent years from second year of tapping, as a percentage of final selection in progenies of 90HP Kuruwita, $91 \mathrm{HP}$ Pallegoda and $96 \mathrm{HP}$ Kuruwita

\begin{tabular}{|c|c|c|c|c|c|c|c|c|}
\hline Criteria & 离 & $\bar{p}$ & $\begin{array}{l}\text { N } \\
\text { d' }\end{array}$ & की & $\begin{array}{l}\text { षे } \\
+ \\
+\end{array}$ & 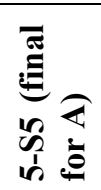 & b & 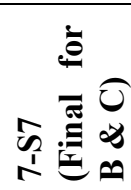 \\
\hline \multirow{3}{*}{$\begin{array}{l}\text { Number of genotypes } \\
\text { added/selected }\end{array}$} & A & 11 & 5 & 2 & 2 & 11 & & \\
\hline & $\mathrm{B}$ & 11 & 3 & 1 & - & 2 & 1 & 11 \\
\hline & $\mathrm{C}$ & 15 & 4 & 6 & 1 & 3 & 1 & 15 \\
\hline \multirow{3}{*}{$\begin{array}{l}\text { Number of genotypes go up to } \\
\text { final selection }\end{array}$} & A & 5 & 4 & 1 & 1 & 11 & & \\
\hline & $\mathrm{B}$ & 6 & 3 & 0 & - & 0 & 1 & 11 \\
\hline & $\mathrm{C}$ & 5 & 2 & 4 & 0 & 3 & 0 & 15 \\
\hline \multirow{3}{*}{$\begin{array}{l}\text { Percentage of selection success }{ }^{a} \\
\text { based on final selection }\end{array}$} & $\mathrm{A}$ & 45.4 & 36 & 9 & 9 & 100 & & \\
\hline & $\mathrm{B}$ & 54.6 & 27.3 & - & - & - & 9 & 100 \\
\hline & $\mathrm{C}$ & 33.4 & 13 & 26 & - & 20 & 0 & 100 \\
\hline \multirow{3}{*}{$\begin{array}{l}\text { Percentage of selection } \\
\text { wastage }^{b} \text { ( } \% \text { out of early } \\
\text { selected genotypes which are } \\
\text { not coming to final) }\end{array}$} & $\mathrm{A}$ & 54.6 & 9 & 9 & 9 & 0 & & \\
\hline & B & 45.4 & 0 & 9 & - & 0 & 0 & 0 \\
\hline & $\mathrm{C}$ & 66.6 & 13.3 & 13.3 & 0 & - & 6 & 0 \\
\hline \multirow{3}{*}{$\begin{array}{l}\text { Percentage } f \text { genotypes missed } \\
\text { by early selection ( } \% \text { of } \\
\text { genotypes not accounting until } \\
\text { final selection) based on final } \\
\text { selection }\end{array}$} & A & & & & 0 & & & \\
\hline & B & & & & 9.2 & & & \\
\hline & $\mathrm{C}$ & & & & 7.7 & & & \\
\hline
\end{tabular}

* Progeny: A - 90HP- Kuruwita, B- 91HP- Pallegoda, C-96HP- Kuruwita

a (No. of genotypes go up to final selection from each selection / No. of genotypes selected at final selection) x 100

$\mathrm{b}$ ((No. of genotypes selected in each selection - No. of genotypes go up to final selection) / No. of genotypes selected at final selection) $\mathrm{x} 100$

c (No. of genotypes selected at final selection - Total no. of genotypes selected in all early selections)/ No. of genotypes selected at final

selection) x 100

When coming to the second selection step (S2), selection success of $81.4 \%$, $81.9 \%$ and $46.4 \%$ was achieved in progenies of 90HP Kuruwita, 91HP Pallegoda and 96HP Kuruwita respectively (Table 3 ). The subsequent selection steps follow the same increasing trend in selection success.

On the other hand the selection wastage was observed as $54.6 \%$ (90HP Kuruwita), 45.4\% (91HP Pallegoda) and $66.6 \%$ (96 Kuruwita) in three progenies, when early selection was 
done at the first step (S1). Also the percentage of missed selection (percentage of genotypes which couldn't get selected during early selection steps until coming to final selection point) is less than $10 \%$ in all three progenies (Table 3). However, the exchange of ranks among selected genotypes was observed. Most of early selections made on clones based on their girth also gave a similar trend (Gonçalves et al, 2006).

If the early selection started from the second year of tapping (S2) instead of S1: as an example, in progeny $90 \mathrm{HP}$ Kuruwita out of eleven genotypes selected at S2 (90-15, 90-2, 90-13, 90-, 90-10, 90-16, 90-4, 90-20, 90-17, 9023 and 90-28), seven genotypes (90-2, $90-13,90-10,90-20,90-17,90-23$ and 90-28) can go up to the final selection point (Table 2a). This selection success based on final selection was $63.6 \%$ and selection wastage was reduced to $36.3 \%$. Similarly, the selection successes were $81.8 \%$ and $33.3 \%$ in progenies 91HP Pallegoda and 96HP Kuruwita respectively. And selection wastage was $18 \%$ in progeny $91 \mathrm{HP}$ Pallegoda whereas it was $66.6 \%$ in progeny 96HP Kuruwita. Therefore breeder can decide the selection step as well.

Figure 3 shows how breeders can use this early selection process to shorten the period of breeding cycle. If early selection is started at step one (S1) it is able to save nearly six to seven years of evaluation period with over $45 \%$ of selection success in two progenies and other progeny, it was around $33 \%$. When early selection started at $\mathrm{S} 1$, nearly 6-7 years get advanced the ECTs/RRI level evaluation. If delayed the early selection, this advancement get reduced, but higher the selection success and lower the selection wastage. However, the breeders have choice on the selection step as well as on the number of genotypes to be selected depending on their requirement, availability of recourses or can be decided on considering mean yield of genotypes compared with mean yield of control clones. 


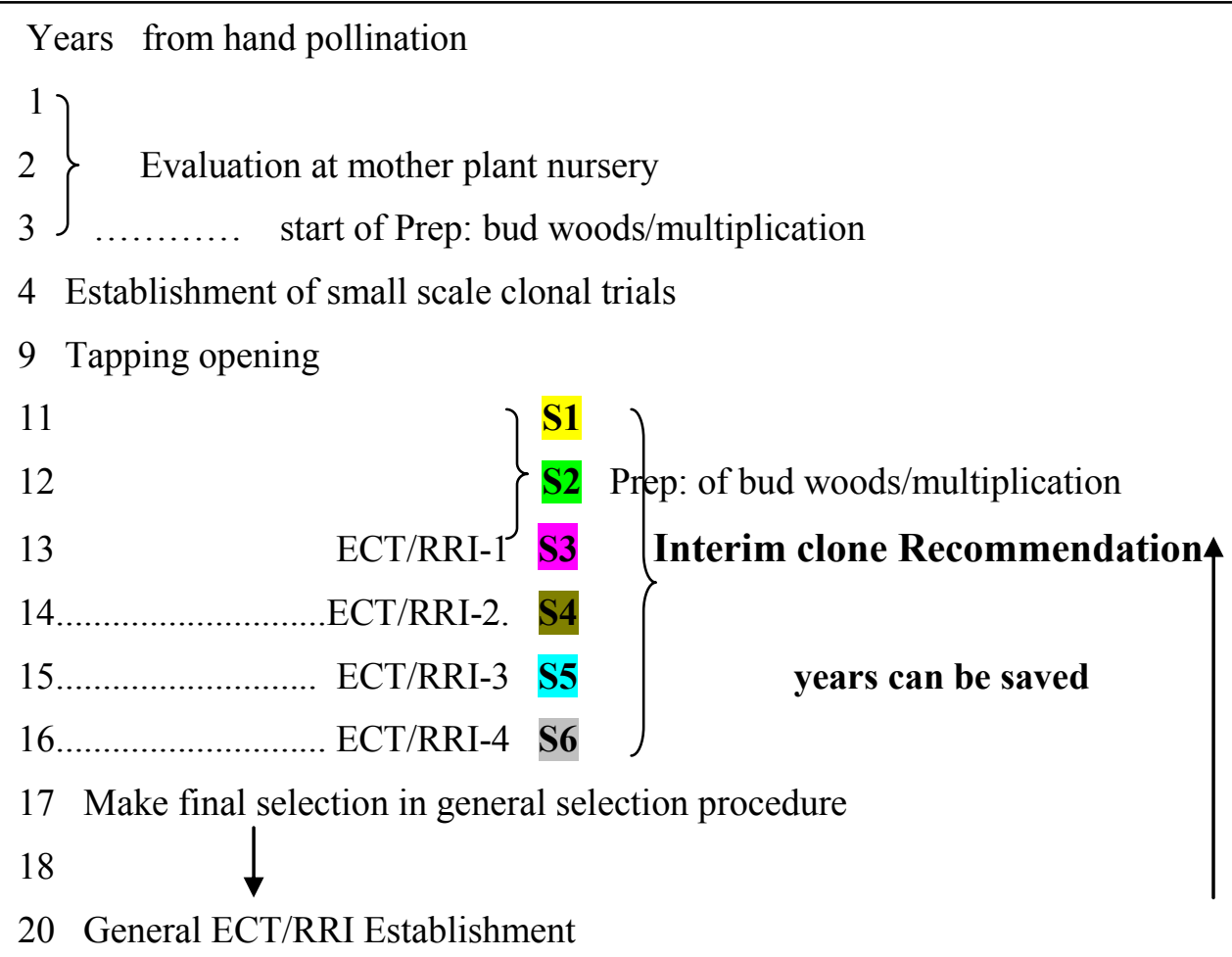

20 General ECT/RRI Establishment

Fig. 3. The time frame of early selections shows the saving of evaluation period, S1- S6: Early selection steps, ECT/RRI 1-4: Early establishments of estate and RRI collaborative trials

During this early selection process, new selections can be included in an "interim clone recommendation", to select clones for Estate; Rubber Research Institute collaborative trial (ECTs/RRI). Then multiplication and establishment of selected genotypes for ECTs/RRI trials can be started, while evaluating small scale trials for another five to seven years to get the final selections. Further multiplication of rejected genotypes during subsequent selection steps can be stopped or eliminated gradually when the desired final selection is applied.

Hence this analysis of yield-yield correlation of 102 genotypes in three different hand pollination progenies 
revealed that there is a strong possibility to select genotypes in advance by evaluating early years yield data. Therefore, in this Hevea genetic improvement program use of interim clone recommendation maximizes the gain per unit time.

\section{Acknowledgments}

The authors thank Dr (Mrs) Wasana Wijesuriya, Biometrician, Rubber Research Institute, for helping in statistical analysis and editing the manuscript.

\section{References}

Adams, W T and Aitken, S (1982). Pacific Northwest tree Improvement Research Cooperative Annual Report. Forest Research Laboratory, Oregan State. 1990-91.

Fisher, R A (1941). Statistical Methods for Research Workers. Olive Rand Boyd, Edinburgh. 316.

Gonçalves, P de S, Bortoletto, N, Fonseca, F da S, Bataglia, O C and Ortolani, A A (1998). Early selection for growth vigour in rubber tree genotypes in Northwestern São Paulo State (Brazil) Genetics and Molecular Biology 21, 515-521.

Gonçalves, P de S, Bortoletto, N, Beleti, C A B, Lima, G L, Reginaldo, R B da C and Luiz, T de M M (2005). Age-age correlation, for early selection of rubber tree genotypes in São Paulo State, Brazil Genetics and Molecular Biology. 28(40) 758-764.

Gonclaves, P de S, Silva, M de A, Gouvêa, L R L and. Junior, J S (2006). Genetic variability for girth growth and rubber yield in Hevea brasiliensis. Scientific Agriculture (Piracicaba, Braz.). 63(3) 246-254

Jayasekara, N E M and Fernando, D M (1984). Progress of Hevea breeding and genetical studies in Sri Lanka. In: Liyanage, A de S and Peries, O S (ed) Souvenir Publication of RRISL. Rubber Research Institute of Sri Lanka.

Matheson, A, Spencer, D J and Magnussen, D (1994). Optimum age for selection in Pinusradiata using basal area under bark for age: age correlations. Silvae Genetica 43, 352-357.

Wu, H X (1998). Study of early selection in tree breeding: advantage of early selection through increase of selection intensity and reduction of field test size. Silvae Genetica 47,146-155.

Address for correspondence: Dr (Mrs) S P Withanage, Head, Genetics \& Plant Breeding Dept., Rubber Research Institute of Sri Lanka, Nivithigalakele, Matugama, Sri Lanka.

e-mail:pamuditharama@yahoo.com 